\title{
The inflammatory potential of diet and bladder cancer risk: results from a prospective cohort study
}

\author{
Christian Daniel Fankhauser ${ }^{1}$, Hugh Mostafid $^{2}$ \\ ${ }^{1}$ Department of Urology, University Hospital, University of Zurich, Zurich, Switzerland; ${ }^{2}$ Department of Urology, Royal Surrey County Hospital, \\ Guildford, UK \\ Correspondence to: Hugh Mostafid. Department of Urology, Royal Surrey County Hospital, Egerton Road, Guildford GU2 7XX, Surrey, UK. \\ Email: Hugh.Mostafid@nhs.net. \\ Provenance: This is an invited article commissioned by Section Editor Xiao Li (Department of Urology, Jiangsu Cancer Hospital \& Jiangsu Institute \\ of Cancer Research \& Nanjing Medical University Affiliated Cancer Hospital, Nanjing, China). \\ Comment on: Abufaraj M, Tabung FK, Shariat SF, et al. Association between Inflammatory Potential of Diet and Bladder Cancer Risk: Results of 3 \\ United States Prospective Cohort Studies. J Urol 2019;202:484-9.
}

Submitted Aug 15, 2019. Accepted for publication Aug 21, 2019.

doi: $10.21037 /$ tau. 2019.08 .32

View this article at: http://dx.doi.org/10.21037/tau.2019.08.32

With an estimated 430,000 new diagnoses and 165,000 deaths per year worldwide (1) and per patient treatment costs of over 100,000 US dollars (2), bladder cancer represents a major burden for patients and society. From a public health perspective, it would be desirable to identify preventable risk factors. One known preventable risk factor for bladder cancer is smoking (1), causing inflammation which is known to play an important role in the biology of many tumors and is considered a hallmark of cancer $(3,4)$. In bladder cancer, inflammation plays a role in prognosis (5) and therapy [e.g., intravesical Bacillus Calmette-Guérin (6) or checkpoint inhibitors (7)].

Inflammation is also influenced by nutrition, which is a known risk factor for several malignancies. However, studies regarding associations between nutrition and bladder cancer report conflicting results (8). Abufaraj et al. report a statistically significant association between a nutrition score related to inflammation and bladder cancer risk in the crude analysis (9). However, this association was attenuated and became non- statistically significant after controlling for known confounders.

The specific nutrition score examined was the Empirical Dietary Inflammatory Pattern (EDIP). This score was developed using reduced rank regression, which is a statistical method that determined linear functions of food groups by maximizing the explained variation in the responses of plasma inflammatory markers (10). Validation of the EDIP in an independent cohort showed only a weak $(r=0.09-0.14)$ association with plasma inflammatory markers (11). Consequently, this score might serve as a proxy for inflammation only to a very limited extent and should therefore be regarded as subject to non-differential misclassification.

However, the absence of evidence of this study may not serve as evidence for absence of a true effect (12): this result could either be based because there is no association or because the study still had insufficient power (sample size and/or follow-up) to demonstrate a significant measure of association. Because carcinogenesis is a slow process, any exposure needs decades to have an impact and because the estimated effect in nutritional/environmental health science tend to be small, the power needs to be huge. This latent effect and expected small effect sizes is a potential explanation for discrepant findings from other observational studies and randomized trials from the same institution $(13,14)$. In conclusion, the authors should be congratulated for pulling together three data set including over 200,000 patients and nearly 5 million person-years of observation and for their continuing efforts to maintain unique cohorts and develop novel metrics of dietary patterns. We believe that nutrition is a promising field and hope that one day recommendations reduce the impact of bladder cancer on individuals and society. 


\section{Acknowledgments}

Dr. Fankhauser is supported by funding from Stiftung für urologische Forschung, Marlis Geiser-Lemken Stiftung, Fonds zur Förderung des akademischen Nachwuchses (FAN), Ernst Göhner Stiftung, SAKK/Dr. Paul Janssen Fellowship, Arnold U. und Susanne Huggenberger-Bischoff Stiftung zur Krebsforschung.

\section{Footnote}

Conflicts of Interest: The authors have no conflicts of interest to declare.

Etbical Statement: The authors are accountable for all aspects of the work in ensuring that questions related to the accuracy or integrity of any part of the work are appropriately investigated and resolved.

\section{References}

1. Ferlay J, Soerjomataram I, Ervik M, et al. GLOBOCAN 2012: Estimated Cancer Incidence, Mortality and Prevalence Worldwide in 2012. Accessed August 9, 2017. Available online: http://globocan.iarc.fr

2. Avritscher EB, Cooksley CD, Grossman HB, et al. Clinical model of lifetime cost of treating bladder cancer and associated complications. Urology 2006;68:549-53.

3. Grivennikov SI, Karin M. Inflammation and oncogenesis: a vicious connection. Curr Opin Genet Dev 2010;20:65-71.

4. Hanahan D, Weinberg RA. Hallmarks of cancer: the next generation. Cell 2011;144:646-74.

Cite this article as: Fankhauser CD, Mostafid H. The inflammatory potential of diet and bladder cancer risk: results from a prospective cohort study. Transl Androl Urol 2019;8(Suppl 5):S491-S492. doi: 10.21037/tau.2019.08.32
5. Masson-Lecomte A, Rava M, et al. Inflammatory biomarkers and bladder cancer prognosis: a systematic review. Eur Urol 2014;66:1078-91.

6. Redelman-Sidi G, Glickman MS, Bochner BH. The mechanism of action of BCG therapy for bladder cancer-a current perspective. Nat Rev Urol 2014;11:153-62.

7. Nadal R, Bellmunt J. Management of metastatic bladder cancer. Cancer Treat Rev 2019;76:10-21.

8. Fankhauser CD, Mostafid H. Prevention of bladder cancer incidence and recurrence: nutrition and lifestyle. Int J Cancer 2015;136:E359-86.

9. Abufaraj M, Tabung FK, Shariat SF, et al. Association between Inflammatory Potential of Diet and Bladder Cancer Risk: Results of 3 United States Prospective Cohort Studies. J Urol 2019;202:484-9.

10. Tabung FK, Smith-Warner SA, Chavarro JE, et al. Development and Validation of an Empirical Dietary Inflammatory Index. J Nutr 2016;146:1560-70.

11. Tabung FK, Smith-Warner SA, Chavarro JE, et al. An Empirical Dietary Inflammatory Pattern Score Enhances Prediction of Circulating Inflammatory Biomarkers in Adults. J Nutr 2017;147:1567-77.

12. Altman DG, Bland JM. Absence of evidence is not evidence of absence. BMJ 1995;311:485.

13. Cook NR, Le IM, Manson JE, et al. Effects of betacarotene supplementation on cancer incidence by baseline characteristics in the Physicians' Health Study (United States). Cancer Causes Control 2000;11:617-26.

14. Wang L, Sesso HD, Glynn RJ, et al. Vitamin E and C supplementation and risk of cancer in men: posttrial follow-up in the Physicians' Health Study II randomized trial. Am J Clin Nutr 2014;100:915-23. 